\title{
An index to assess and monitor the progression of wasting disease in eelgrass Zostera marina
}

\author{
David M. Burdick, Frederick T. Short, Jaimie Wolf \\ Department of Natural Resources and Jackson Estuarine Laboratory, University of New Hampshire, Durham, \\ New Hampshire 03824, USA
}

\begin{abstract}
An index based on a rapid visual determination of the relative amount of necrotic tissue on eelgrass shoots infected with wasting disease is described. The utility of the index for assessing and monitoring disease levels in natural and experimental populations of eelgrass is illustrated with examples from the field and a mesocosm experiment. Using the Wasting Index, monitoring of the disease along with environmental variables provided correlational data that aided understanding of the disease progression and linked disease severity with salinity. Once salinity increased above a threshold, disease spread rapidly and was inversely correlated with leaf area (infection phase). Following the initial peak of disease, the Wasting Index was positively correlated with leaf area (wasting phase). Declines in salinity below the threshold (caused by precipitation or spring runoff) allowed eelgrass recovery and reset the host-pathogen system.
\end{abstract}

\section{INTRODUCTION}

Eelgrass Zostera marina $\mathrm{L}$. is a submerged angiosperm that forms the basis of a specialized coastal and estuarine habitat of great ecological value (Phillips 1984, Thayer et al. 1984). With roots in the sediment and thin, strap-like leaves that can extend over $2 \mathrm{~m}$ into the water column, eelgrass populations form underwater meadows. Eelgrass supports complex trophic food webs by virtue of both its physical structure and primary production, and is best known for its role as a breeding ground and nursery for important finfish and shellfish populations (Thayer et al. 1975, Short \& Short 1984).

Currently, eelgrass populations around the world are declining dramatically due primarily to 2 causes: excess nutrient pollution and a recurrence of wasting disease (Short et al. 1986, 1991). Anthropogenic damage to eelgrass populations is thought to occur primarily through nutrient loading and subsequent eutrophication of estuarine and coastal waters (Orth \& Moore 1983, Twilley et al. 1985, Short et al. 1989, 1992). However, the focus of this paper is wasting disease, which has dramatically reduced eelgrass populations in some estuaries along the east coast of the U.S. in the last decade (Short et al. 1989).
The current eelgrass wasting disease, discovered along the U.S. east coast in 1984 (Short et al. 1986), first appears as small black spots on eelgrass leaves; the spots spread and coalesce, and finally cause death to the shoot or plant. In the Great Bay Estuary on the Maine-New Hampshire border (USA), many eelgrass beds have disappeared due to this disease within the past decade (Short et al. 1986, 1987). In the western North Atlantic, evidence of the disease was found as far south as Beaufort, North Carolina, USA, and as far north as Nova Scotia, Canada (Short et al. 1987). Recently the infectious disease was found to be cosmopolitan in distribution (Roscoff, France; Puget Sound, USA; Moroiso Bay, Japan). The symptoms and progress of the disease are similar to those described during the major eelgrass decline in the 1930s (Short et al. 1988). The eelgrass decline of the 1930s has been described as a major natural catastrophe (Milne \& Milne 1951 . Johnson \& Sparrow 1961, Rasmussen 1977, den Hartog 1987 ). The actual cause of the 1930 s wasting disease was never determined, but the impact of that decline on the Great Bay Estuary, among other places, indicated that eelgrass functions as a filter of sediments, nutrients, and pollutants in Great Bay and promotes a healthy, productive estuary (Jackson 1944, Short \& Short 1984). 
Recently, the organism responsible for causing the current wasting disease has been identified. Through the completion of Koch's postulates it has been shown that a protozoan from the genus Labyrinthula is the causal organism producing the eelgrass infection (Short et al. 1987). Subsequent studies of the disease organism have shown that only 1 species of Labyrinthula is responsible for causing the wasting disease, and this species has been named Labyrinthula zosterae (Muehlstein et al. 1988, 1991). We describe here a rapid method to assess wasting disease infection so that the progression of the disease may be monitored in cultures and field populations. These data can be used to determine disease-related mortality and quantify L. zosterae infection in studies of the relationship between eelgrass and this pathogen.

\section{METHODS}

Labyrinthula zosterae, a slime mold pathogen, has been isolated from blackened, necrotic eelgrass leaf tissue collected from the field and mesocosm tanks according to the methods outlined by Muehlstein et al. (1988). Following isolation of disease from characteristic black spots, reinfection of healthy leaf tissue on agar plates was achieved in $100 \%$ of 45 replicates (Short et al. 1987). Occasionally, disease appearing on very young leaves was light brown, rather than black. The disease has also been cultured from these lighter spots and they have regularly been included in estimations of the disease infection on the leaves. Leaf necrosis can also occur from extended direct sunlight, age, and leaf cracking, but these spots are characteristic of each type of damage and not easily confused with spots from disease. The characteristics and progression of disease symptoms on eelgrass leaves have been previously described (Short et al. 1986, 1987, Muehlstein et al. 1988).

The degree of infection on individual shoots, and by extension for entire populations, can be estimated by a relative measure of infection area termed the Wasting Index (WI). Based on agricultural methods of assessing plant damage by pathogens (James 1971), the percentage of leaf tissue that has become necrotic is approximated for each leaf on a vegetative shoot. A digitized key showing different levels of disease is useful as a guide for those indexing the shoots (Fig. 1), with the degree of interpolation dictated by the discrimination of the sampler (James 1971). Individual samplers introduce a degree of variability, but extensive agricultural applications have shown that such index data provide a valid measure of disease (James 1971). Leaf sheaths are not included (they rarely become infected), since they are not accessible for the youngest leaves. The percentage of infected area for the most infected leaf of each shoot is averaged for all shoots in the sample to obtain the Wasting Index. This index reflects the degree of infection in an eelgrass population at the time of sampling

An alternative expression of the index, which has more desirable variance qualities (because each observation is a mean), but has been less useful in understanding the disease (because the range of disease index values is smaller), is termed the Whole Shoot WI. Here, the average percentage infection of all the leaves is calculated for each shoot, and the mean of the shoot averages for a sample of several shoots is the Whole Shoot WI. The Wasting Index is presented as the primary measure of wasting disease extent, but the Whole Shoot WI may prove useful in future studies.

It is important to use only mature, terminal shoots to estimate population infection. Our observations indicate that leaf-to-leaf contact is required for infection of new leaves or shoots. A young, lateral shoot is often protected from physical contact with diseased tissues since it originates within a sheath of the terminal shoot. Analysis of the data at the conclusion of our study showed that for the population estimate to fall within 1 standard error of the mean of 20 shoots more than $95 \%$ of the time, 14 shoots must be indexed.

To determine the condition of an eelgrass population at the time of indexing, average leaf area above the sheath of each shoot is obtained by measuring the distance from the youngest root node to the sheath of the youngest fully expanded leaf (usually the third or fourth leaf), the distance from the youngest root node to the tip of each leaf, and the width of a representative leaf (third or fourth youngest). Thus: Leaf Area = $\sum$ (Leaf Lengths - Sheath Length) $\times$ Leaf Width.

Mesocosm tanks allow repeated examination of disease in eelgrass over time and under controlled conditions for comparison to field results (Short 1985, 1987). The mesocosm apparatus consisted of $1.5 \times 1 \times 0.8 \mathrm{~m}$ tanks (length $\times$ width $\times$ height) supplied with running fresh water, seawater from Great Bay, and a circulation pump. The tank cultures were outdoors and had natural light regimes and ambient temperature conditions. Sediment was collected from sites supporting eelgrass in the field and mixed with sand $(1: 1)$. Eelgrass from field populations was transplanted at 200 shoots $\operatorname{tank}^{-1}$ in the spring and grew to over 600 shoots $\mathrm{m}^{-2}$ by mid-summer. The 10 plants that were repeatedly indexed were grown in plastic cylindrical pots $(7 \times 7 \mathrm{~cm}, 1$ plant per pot and each pot placed within the vegetated mesocosm) so they could be removed from the mesocosm for disease assessment. Following indexing $(<5 \mathrm{~min})$, the pots were replaced on bare sediment among other shoots. Water salinity was monitored with a temperature-compensating optical refractometer (American Optical). 
WASTING INDEX METHOD

Introduction: The purpose of the wasting index is to provide a rapid procedure to quantify the disease on an eelgrass shoot. Shoots are collected to represent the population under study, and should be rinsed with fresh water to halt disease spread.

A. Enter the date the shoots were collected under 'Date', the location and site of collection under 'Site', and the person collecting the eelgrass and measuring the disease under 'Person'.

B. Select a terminal, vegetative shoot and number it. Enter the number on the data sheet under 'Shoot \#'

C. Measure the shoot width in millimeters (e.g. 3.2) and enter under 'Width'.

D. Measure the height of the youngest visible sheath (usually encloses the youngest 2 to 3 leaves) from the youngest root node in centimeters (e.g. 14.7) and enter under 'Sheath'

E. Number the leaves of each shoot from youngest to oldest.

\section{WASTING INDEX KEY}

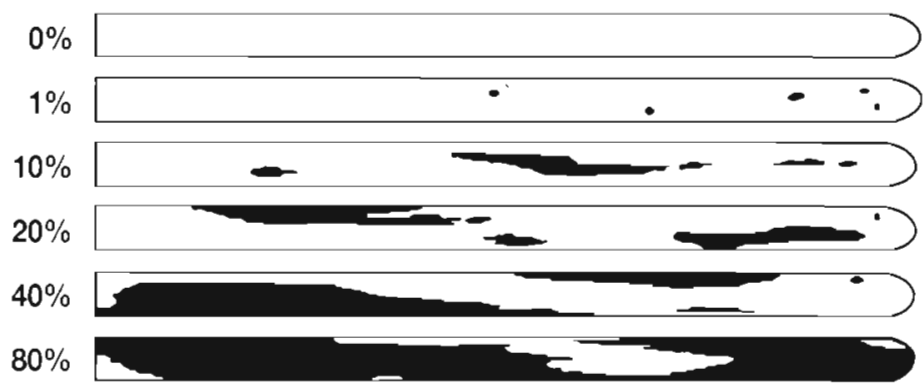

F. Measure the length of each leaf from the youngest root node to the tip in centimeters (e.g. 54.9) and enter under 'Length'. If the tip is broken, measure to the break and write 'BT' next to the measurement.

G. Enter the percentage of disease on the leaf under 'Index'. The percentage of disease on a leaf is estimated by examining the portion of the leaf from the top of the sheath to the tip, then comparing the disease areas on the leaf to the 'Wasting Index Key'. The diseased areas for $0,1,10,20,40$, and $80 \%$ infection are shown. Interpolate if the leaf appears to have a percentage of the disease between the numbers on the key (e.g. $3 \%$ or $65 \%$ ).

$\mathrm{H}$. Enter noteworthy observations under 'Comments'.

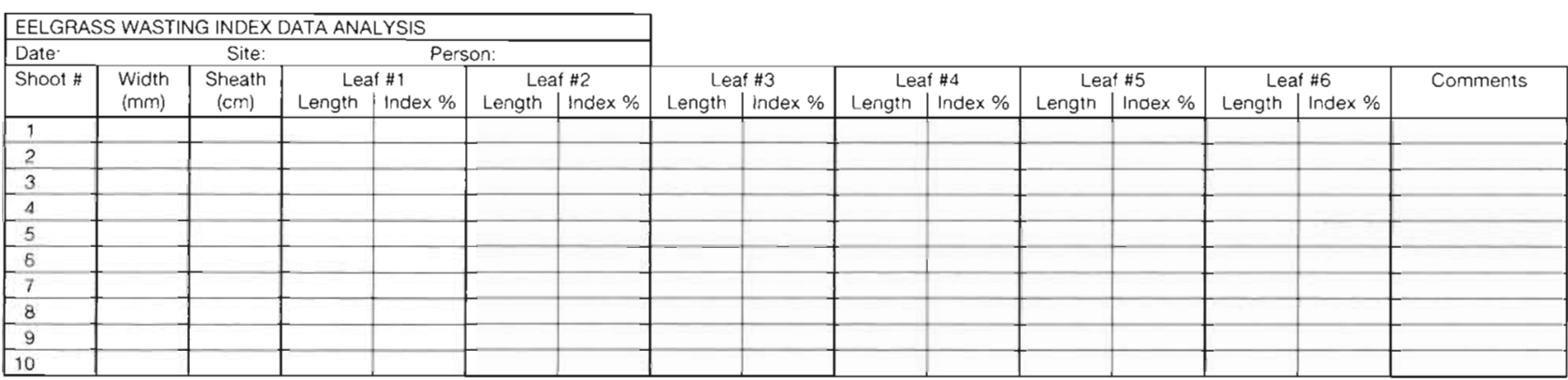

Fig. 1. A protocol for the Wasting Index method

Great Bay is a shallow, tidally dominated estuary in the Piscataqua River watershed of New Hampshire (Fig. 2). Our long-term site for monitoring wasting disease in Great Bay is a persistent eelgrass bed west of the first channel marker ( $N$ ' 6 ') near the mouth of Great Bay. This small oval-shaped meadow is at the head of the first channel bifurcation in the bay. Wasting disease was assessed in 7 to 20 (mean $=16)$ mature, terminal shoots monthly in the winter (December through March), and twice per month during the active growing season for 1990. Salinity was continuously monitored (InterOcean Systems temperature/salinity meter, Model 541; every $10 \mathrm{~min}$ ) and averaged for each week. Precipitation was measured daily at a site adjacent to Great Bay (Fig. 2), and the data were averaged for each week.

\section{RESULTS AND DISCUSSION}

Progression of wasting disease for a plant grown in a mesocosm is illustrated in Fig. 3, showing the initial in- fection and advance of the disease over the leaves until death occurred. Typically, small black spots first appear, usually on the older, outer leaves. As Labyrinthula zosterae spreads through the leaves, the spots grow and coalesce. The younger, inner leaves become exposed to the disease either from the diseased outer leaves, neighboring shoots, or from diseased leaves adrift in the water column. At this point the plant may release (dehisce) outer, diseased leaves. Once the youngest or second youngest leaf has a significant amount of infection (20 to $40 \%$ ), the plant usually dies. We define 2 phases of the disease phenomena: the infection phase, a period when rapid disease spread is coincident with a sharp reduction in total shoot leaf area, and the wasting phase, a period when the disease spread is slow and tracks with leaf area.

Progression of the disease in the field was followed by examining sets of shoots collected periodically from Great Bay during 1990 (Fig. 4). Plants with the disease were present throughout the year, but the standing 


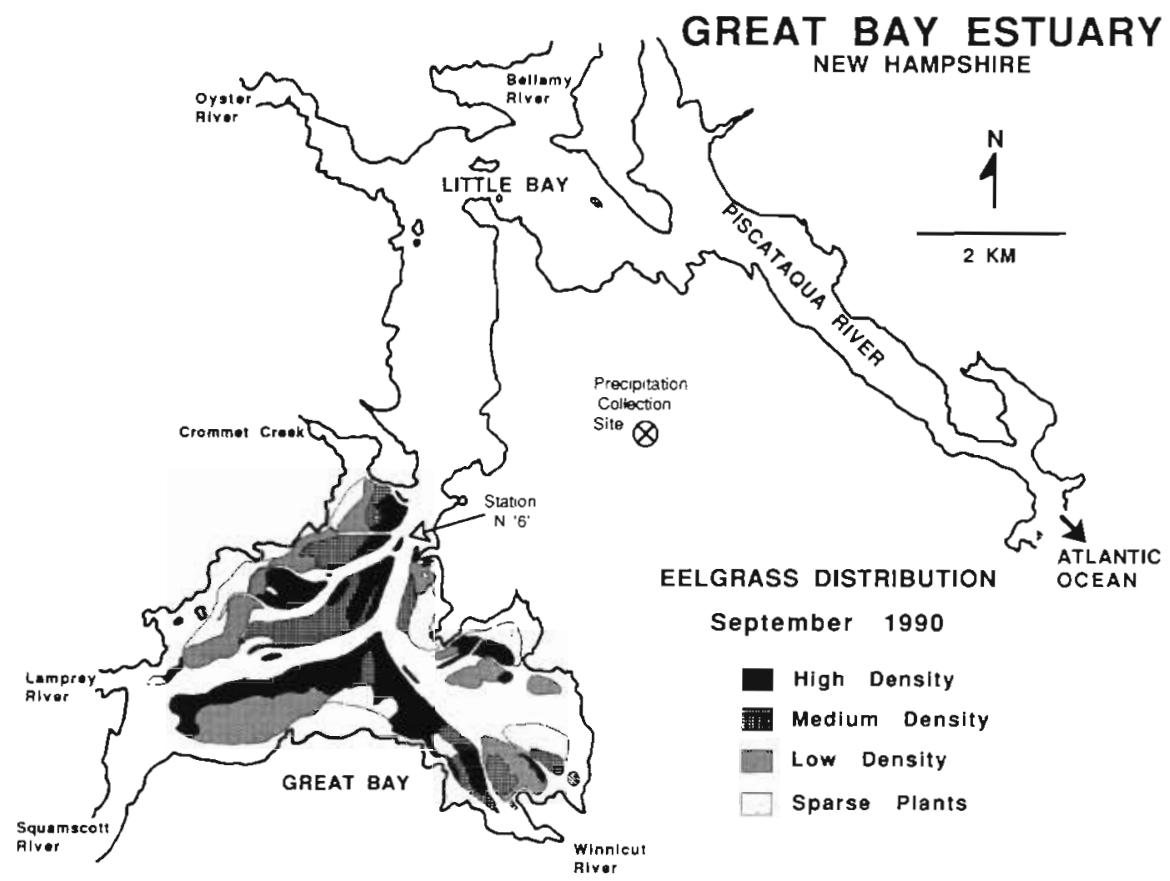

Fig. 2. Zostera marina. Eelgrass distribution and sampling location in Great Bay, New Hampshire, USA.

stock of the shoots was lowest in winter (as indicated by leaf area). Incidence of the disease was also low in winter, but was lowest following the burst of rapid shoot growth in spring (Julian Days 100 to 150). As

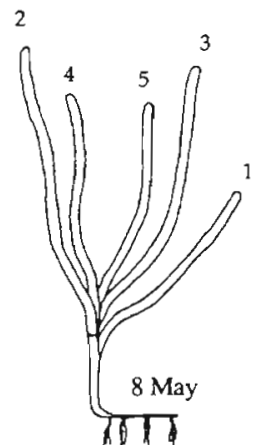

तोा

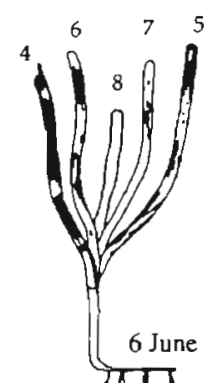

ताI
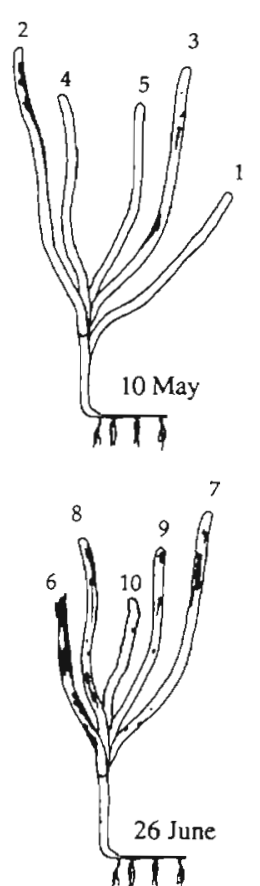
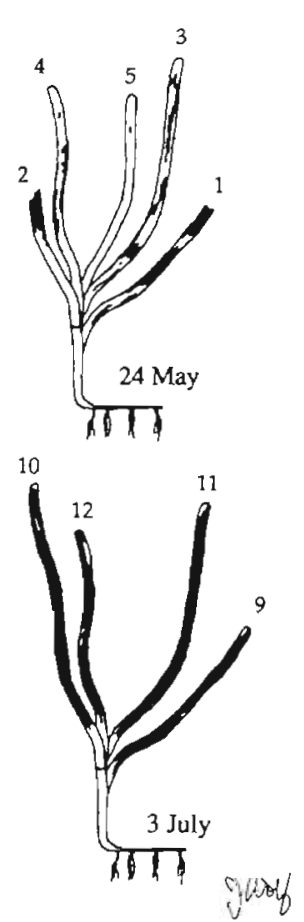

Fig. 3. Zostera marina infected with Labyrinthula zosterae. Progression of wasting disease in a typical eelgrass plant growing in a high salinity mesocosm. Leaves are numbered ( $1=$ oldest), so that diseased areas may be traced over time. The plant died from disease 2 mo after introduction of $L$. zosterae infection spread in the plants during June and July (infection phase; Days 150 to 200), the outer diseased leaves dehisced, as indicated by the decline in leaf area (Fig. 4). The release of diseased leaves was apparent from large rafts of floating leaves and the occurrence of low eelgrass abundance when eelgrass beds were mapped (Fig. 2). During this period of rapid infection, the Wasting Index was negatively correlated with leaf area (Fig. 5a) indicating plant growth could not keep pace with the spread of the infection.

From mid-July (Day 200) to the following February, the Wasting Index of the field population was positively correlated with leaf area (Fig. 5b) and was associated with slower infection rates and declining standing stock, but long-term survival of the populations. We have termed this period when populations are declining and Wasting Index correlates with leaf area the wasting phase (Fig. 4). It is likely that some shoots were killed by the disease during this phase, but only survivors remained to be sampled since we randomly collected live shoots on each sampling date. The fate of infected shoots in the population is not assessed by this sampling methodology.

Salinity has been proposed as a factor affecting the disease-related dieoff of eelgrass (Stevens et al. 1950, Martin 1954, Short et al. 1986), but its overall role remains difficult to assess. The effect of salinity on disease spread in eelgrass is suggested by the rapid increase in Wasting Index during a period of increase in salinity from 15 to $25 \mathrm{ppt}$ (Fig. 4). Further evidence for salinity control of disease spread comes from mesocosm research. 
Fig. 4. Zostera marina infected with Labyrinthula zosterae. Seasonal progression of infection in an eelgrass population by wasting disease and its relation-ship to shoot leaf area and salinity in Great Bay in 1990

Monitoring salinity and wasting disease of eelgrass in a mesocosm supplied with seawater from Great Bay (residence time ca $0.5 \mathrm{~d}$ ) showed the effect of salinity on the spread of infection in an eelgrass population (Fig. 6). Monitoring of infection began on 16 June 1987 (Julian Day 167) for 10 plants. The Wasting Index quickly reached a peak during the first infection phase, then fell and remained low through Day 200. During the first infection phase, leaf area declined as plants dropped their older, infected leaves, but rebounded after the incidence of the disease became low (Day 182), suggesting the plants began to outgrow the disease at this time. The salinity in the tank was at 25 ppt during the first infection phase, then fell below
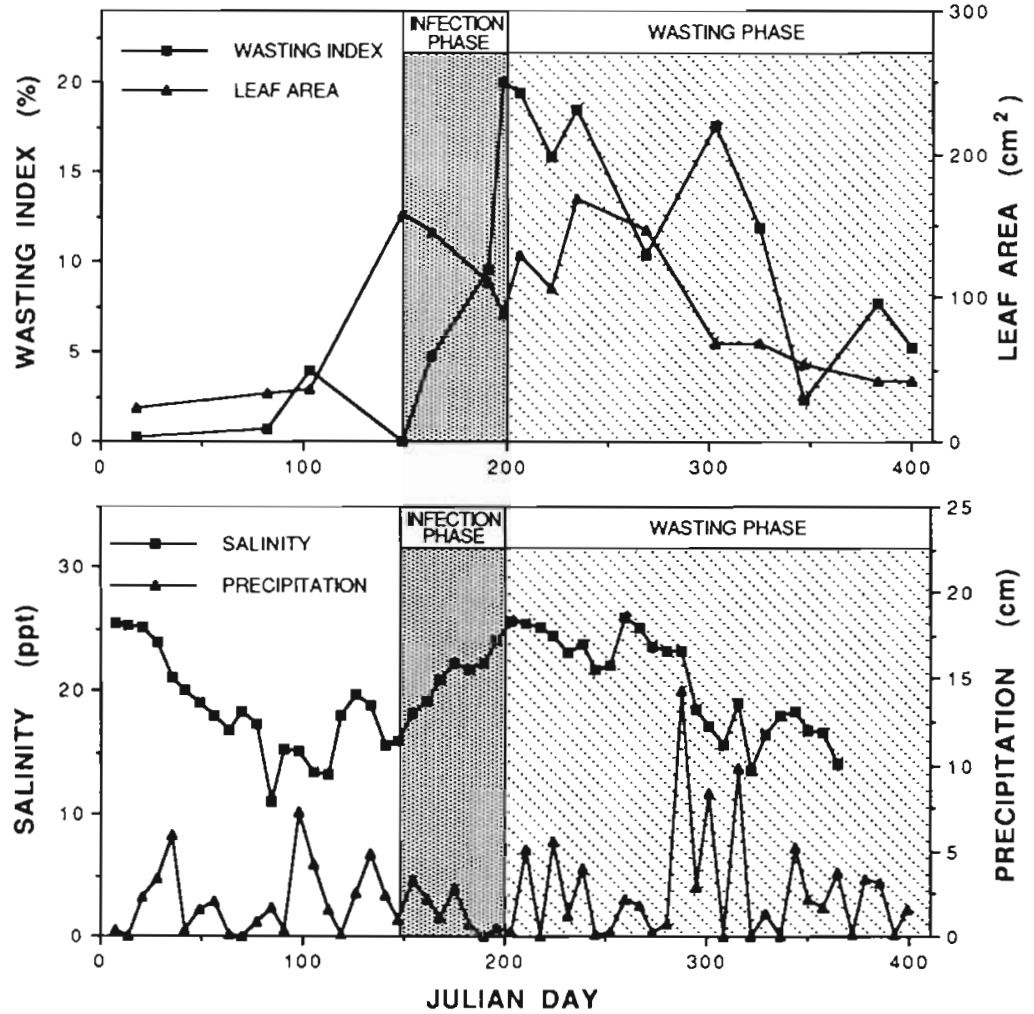
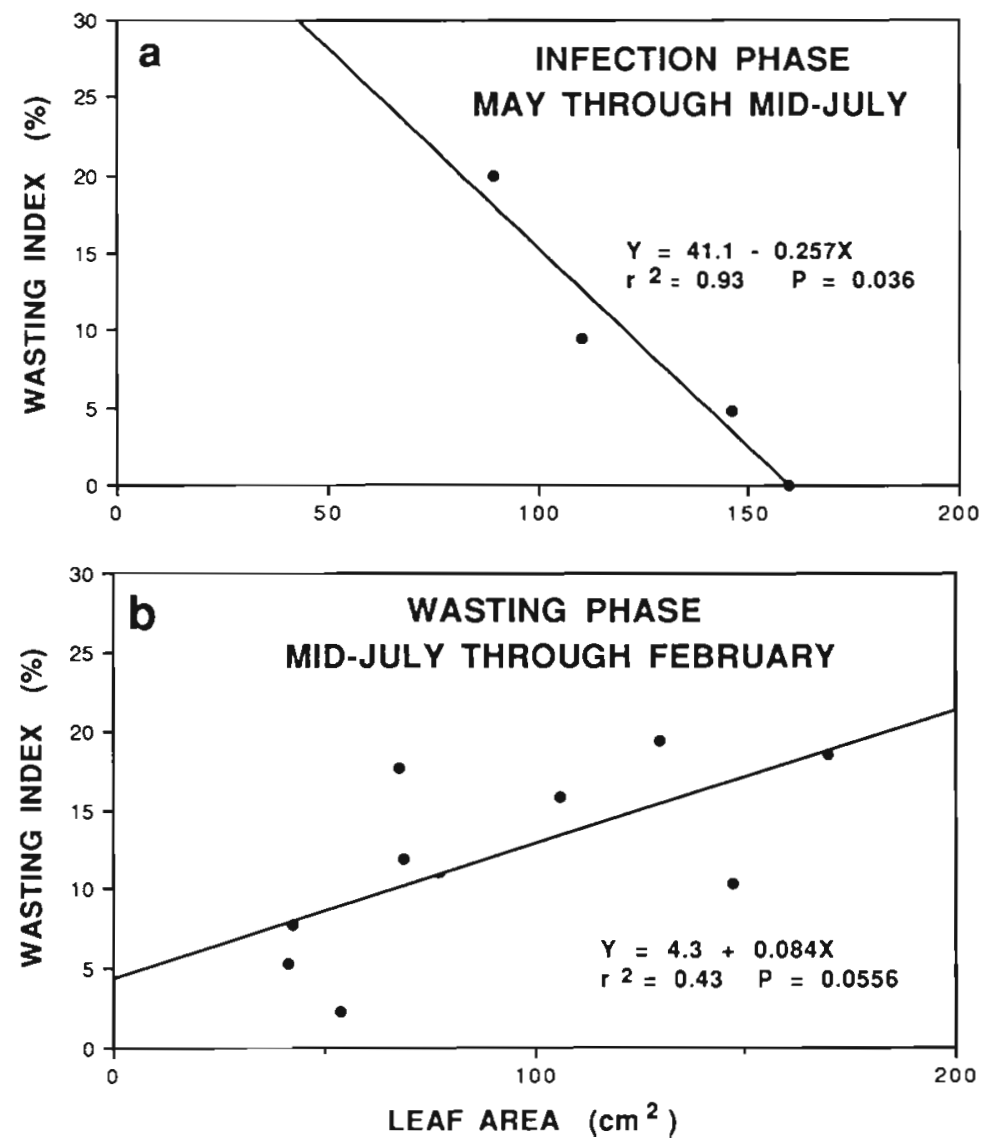

25 ppt on Day 177 to a minimum of 21 ppt on Day 184, and remained below 25 ppt through Day 195, whereupon it increased fairly steadily through Day 250 (Fig. 6). During the period of lowered salinity, the Wasting Index remained low and variable (ca $22 \%$ ), but increased rapidly to over $60 \%$ following the increase in salinity on Day 195.

Rapid increase in infection of the mesocosm population following Day 200 was initially accompanied by decreased leaf number and area (second infection phase). Subsequently, the Wasting Index declined along with leaf area, and both reached a nadir around Day 280 (second wasting phase; Fig. 6). As in the field, the second onset of infection with Labyrinthula zosterae showed a negative correlation between eelgrass infection and leaf area (Days 202 to 213), until declining leaf area was accompanied by declining disease (Days 213 to 318 ).

Fig. 5. Zostera marina. Changing relationship between Wasting Index and leaf area above sheaths in a field population of eelgrass, 1990. (a) Infection phase, data for May (Day 150) to mid-July (Day 200); (b) wasting phase, data from mid-July (Day 200) to February (Day 400). Data from Fig. 4 

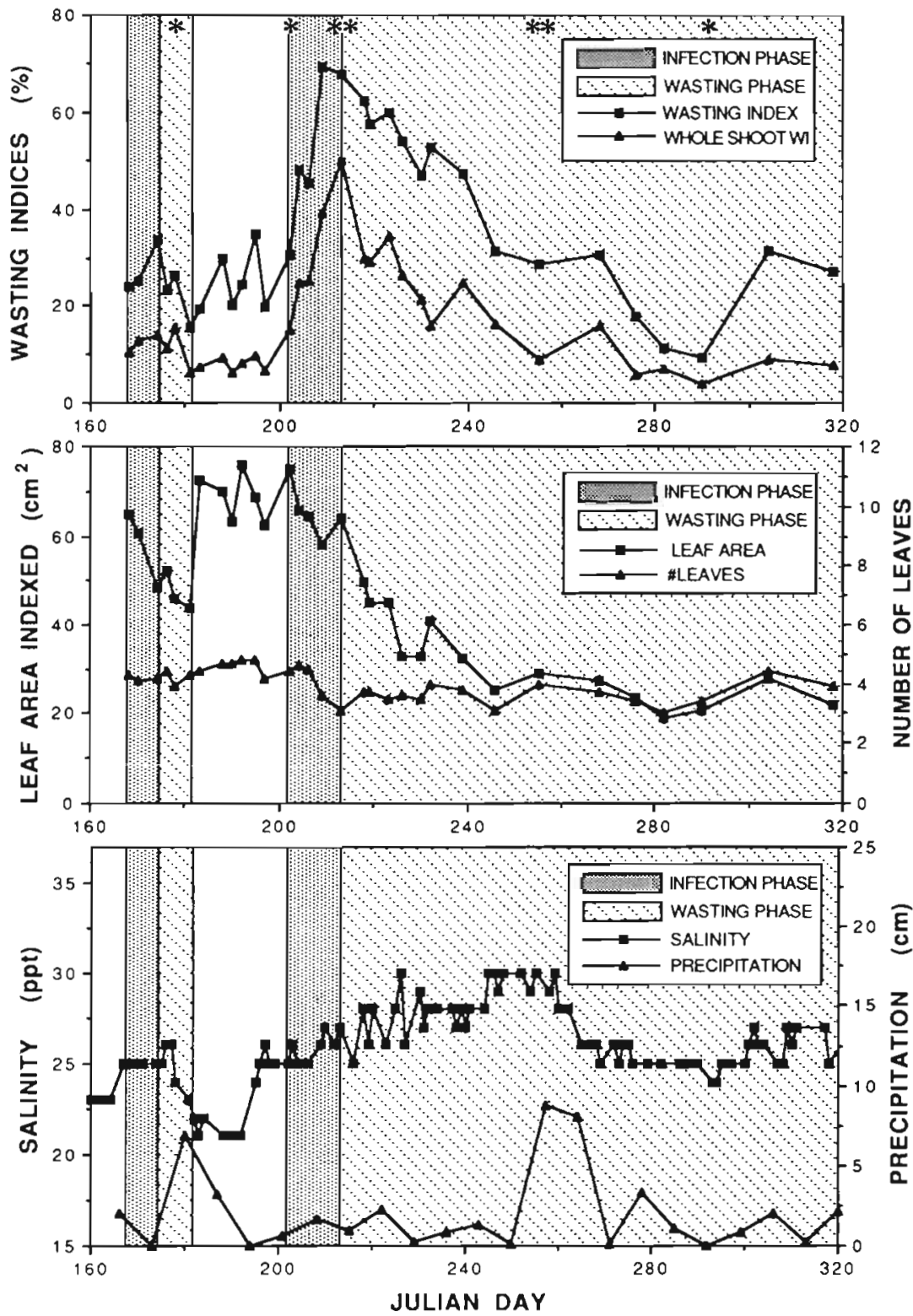

Fig. 6. Zostera marina infected with Labyrinthula zosterae. Progression of infection in an eelgrass population by the wasting disease (using both the Wasting Index and the Whole Shoot WI), number of leaves and leaf area per shoot of 10 plants, and salinity in a mesocosm supplied with ambient seawater from Great Bay, 1987. Asterisks denote time of plant death

Multiple regression analyses showed leaf area indexed the most important descriptor of Wasting Index, but salinity was also significant for both phases (Table 1). That is, once the salinity was high enough to support rapid infection (Day 196), the disease spread faster than the shoots could make new leaves until shoot size was so reduced that continued spread from leaf-to-leaf contact was severely curtailed (Day 213), whereupon disease tracked with leaf area. This latter phase was associated with long-term survival for some shoots but death for others (see below), thus resulting in a reduction of population density as well as shoot biomass.

As discussed earlier, the pattern of infection appears to be dependent upon a controlling variable with a threshold: salinity of the surrounding water, which must be high enough to support rapid disease spread. Diseased and disease-free stocks of eelgrass are routinely maintained in mesocosms at the Jackson Estuarine Laboratory (Durham, New Hampshire) by controlling salinity $(<12$ ppt for disease-free plants, $>20$ ppt for diseased plants). Light may be important as a secondary factor, influencing plant activity and altering the hostpathogen relationship. In the field where there is less available light, salinities $>20$ ppt were associated with the rapid spread of Labyrinthula zosterae, whereas in the light-saturated mesocosm tanks, 25 ppt appeared to be the lower salinity limit for rapid disease spread (see Short et al. 1991). Earlier work that measured the spread of pathogenic L. zosterae cultures on agar plates found poor growth at 10 ppt and no growth at 0 and 5 ppt salinity (Muehlstein et al. 1988). Excised leaves inoculated with disease exhibited necrosis rapidly at 26 and 36 ppt salinity, but took $48 \mathrm{~h}$ at 14 ppt salinity; at 10 ppt only limited infection was observed (in 2 of 16 replicates; Muehlstein et al. 1988). Additionally, $3 \mathrm{wk}$ following inoculation of eelgrass plants with the disease in flasks, plant survival was $25 \%$ at 30 ppt but $100 \%$ at 10 ppt salinity (Short et al. 1986). Apparently, salinity acts as a lower limit, stopping L. zosterae activity at $<10 \mathrm{ppt}$, but also inhibiting pathogenicity in eelgrass at salinity levels below 20 to 25 ppt. Further investigation of plant susceptibility to the pathogen at salinities between 10 and $30 \mathrm{ppt}$ and at different light levels is needed.

In July, 4 of the 10 plants indexed regularly in the mesocosm were killed by wasting disease, including 1 that died soon after the first infection phase, and 3 more that died during the second infection phase (Fig. $6)$. These plants were replaced on Day 202 (1 plant) and Day 217 ( 3 plants). During the wasting phase, 3 
Table 1. Zostera marina. Results from multiple regression analyses of the Wasting Index (dependent variable) described as a function of Leaf Area and Salinity (independent variables) using data from a mesocosm population during infection and wasting phases

\begin{tabular}{|c|c|c|c|c|c|c|c|c|c|}
\hline \multirow[t]{2}{*}{ Phase } & \multicolumn{5}{|c|}{ Overall } & \multicolumn{2}{|c|}{ Leaf area $\left(\mathrm{cm}^{2}\right)$} & \multicolumn{2}{|c|}{ Salinity (ppt) } \\
\hline & $\mathrm{n}$ & $\mathrm{R}^{2}$ & $F$ & $\mathrm{p}$ & Intercept & Coefficient & $\mathrm{p}$ & Coefficient & $\mathrm{p}$ \\
\hline Infection & 5 & 0.99 & 76.0 & 0.0130 & -77.5 & -1.69 & 0.0201 & +9.37 & 0.0298 \\
\hline Wasting & 16 & 0.87 & 42.3 & 0.0001 & -65.0 & +1.30 & 0.0001 & +2.26 & 0.0440 \\
\hline
\end{tabular}

other plants died, making a total of $50 \%$ mortality from disease for July through October. In the mesocosm, the response of the individual shoots was similar to that of the population during the infection phase, when disease spread was countered by leaf dehiscence. That is, all shoots became infected and dehisced their diseased outer leaves. However in the wasting phase, when decreased leaf area was accompanied by decreased disease at the population level, individual shoots died if production of new leaf tissue was low, but survived if leaf production was high.

The 2 phases of the wasting disease have distinct characteristics and merit further study. In our mesocosm experiment, the rate of shoot death over time was greater during the infection phase. We hypothesize that a prolonged or more intense infection phase would result in catastrophic eelgrass dieoff, and may explain why entire populations succumb to wasting disease and disappear, as has been observed (Short et al. 1986). By contrast, a less severe infection phase (e.g. Fig. 4), could produce the thinning responsible for vast areas of reduced standing stock (Fig. 2).

\section{CONCLUSIONS}

The Wasting Index provides a mechanism for quantitatively assessing disease in eelgrass populations in a diagnostic framework. Use of the index on natural or cultured eelgrass populations provides a tool for understanding the characteristics of disease-plant interaction. Such analysis has led to the identification of 2 phases of the wasting disease: a time of rapid spread when leaf area quickly declines (infection phase), and a time when disease spreads slowly and disease incidence tracks with eelgrass leaf area (wasting phase). These 2 phases may reflect the 2 types of disease impacts observed in the field: complete disappearance of eelgrass beds, and widespread thinning of beds respectively.

The Wasting Index has proven useful in experimental work that investigates environmental and biological controls on the susceptibility of eelgrass to infection and death from Labyrinthula zosterae (Short et al. 1992). Routine disease assessment has provided insight into the control of wasting disease by salinity. That is, decreases in salinity below a threshold (20 to 25 ppt) reduced wasting disease activity, and apparently allowed eelgrass to recover from infection through regrowth.

The response of eelgrass to disease can be assessed repeatedly in mesocosms, in field transplants, or in natural populations using the Wasting Index. The susceptibility of specific plants, selected or genetically engineered for disease resistance, may be evaluated quantitatively using the Wasting Index. Further work will focus on using the index to predict die-offs from the wasting disease in field populations.

Acknowledgements. The authors thank David Porter, Robert Buchsbaum, Tom Harrington, Mike Morrison, Yvette Piceno, and Ed Brainard for help in the development of the Wasting Index, Phillip Canter for precipitation data, and Cathy Short for editorial comments. This research was funded by the National Estuarine Research Reserve Program of the Marine Sanctuaries Division (\#NA87AA-D-CZ018, \#NA90AA-DCZ400) and the Estuarine Habitat Program of the Coastal Ocean Program (\#NA90 AA-D-SG458), both of the National Oceanic and Atmospheric Administration of the Department of Commerce. Jackson Estuarine Laboratory contribution number 266.

\section{LITERATURE CITED}

den Hartog, C. (1987). 'Wasting disease' and other dynamic phenomena in Zostera-beds. Aquat. Bot. 27: 3-14

Jackson, C. F. (1944). Physical and biological features of Great Bay and the present status of its marine resources. No. 1. A biological survey of Great Bay, New Hampshire. New Hampshire Marine Fisheries Commission, Durham

James, W. C. (1971). An illustrated series of assessment keys for plant diseases - their preparation and usage. Can. Plant Dis. Surv. 51: 39-65

Johnson, T. W. Jr, Sparrow, F. K. Jr (1961). Fungi in oceans and estuaries. J. Cramer, Weinheirm

Martin, A. C. (1954). A clue to the eelgrass mystery. Trans. N. Am. Wildl. Conf. 19: 441-449

Milne, L. J., Milne, M. J. (1951). The eelgrass catastrophe. Scient. Am. 184: 52-55

Muehlstein, L. K., Porter, D., Short, F. T (1988). Labyrinthula sp., a marine slime mold producing the symptoms of wasting disease in eelgrass, Zostera marina. Mar. Biol. 99: 465-472

Muehlstein, L. K., Porter, D., Short, F. T (1991), Labyrinthula zosterae sp. nov., the causative agent of wasting disease of eelgrass, Zostera marina. Mycologia 83: 180-191 
Orth, R. J., Moore, K. A. (1983). Chesapeake Bay: an unprecedented decline in submerged aquatic vegetation. Science 22: $51-52$

Phillips, R. C. (1984). The ecology of eelgrass meadows in the Pacific Northwest: a community profile. U.S. Fish Wildl. Serv, Res. Rep. FWS/OBS-84/24

Rasmussen, E. (1977). The wasting disease of eelgrass (Zostera marina) and its effects on environmental factors and fauna. In: McRoy, C. P., Helfferich, C. (eds.) Seagrass ecosystems: a scientific perspective. Marcel Dekker, New York, p. 1-52

Short, F. T. (1985). A method for the culture of tropical seagrasses. Aquat. Bot. 22: 187-193

Short, F. T. (1987). The effects of sediment nutrients on seagrass growth and morphology. Aquat. Bot. 27: 41-57

Short, F. T., Burdick, D. M., Wolf, J., Jones, G. E. (1993). Eelgrass in estuarine research reserves along the east coast, U.S.A. Part I: Declines from pollution and disease, and Part II: Management of eelgrass meadows. NOAA, Coastal Ocean Program Publication, Washington, $\mathrm{DC}$

Short, F. T., Ibelings, B. W., den Hartog, C. (1988). Comparison of a current eelgrass disease to the wasting disease of the 1930s. Aquat. Bot. 30: 295-304

Short, F. T., Jones, G. E., Burdick, D. M. (1991). Seagrass decline: problems and solutions. In: Bolton, H. S. (ed.) Coastal wetlands. Am. Soc. Civil Eng., New York, p. $439-453$

This article was presented by G. W. Thayer, Beaufort, N. Carolina, USA
Short, F. T., Mathieson, A. C., Nelson, J. I. (1986). Recurrence of an eelgrass wasting disease on the border of New Hampshire and Maine. Mar. Ecol. Prog. Ser. 29: 89-92

Short, F. T., Muehlstein, L. K., Porter, D. (1987). Eelgrass wasting disease: cause and recurrence of a marine epidemic. Biol. Bull. 173: 557-562

Short, F. T., Short, C. A. (1984). The seagrass filter: purification of estuarine and coastal waters. In: Kennedy, V. S. (ed.) The estuary as a filter. Academic Press, New York, p. $395-413$

Short, F. T., Wolf, J., Jones, G. E. (1989). Sustaining eelgrass to manage a healthy estuary. Proc. Sixth Symp. Coast. Ocean Manag. Am. Soc. Civil Eng., New York, p. $3689-3706$

Stevens, N. E., Ellis, H. R., Stevens, R. B. (1950). Wasting and recovery of Zostera marina on the Atlantic coast of the United States. Plant Dis. Rep. 34: 357-362

Thayer, G. W., Kenworthy, W. J., Fonseca, M. S. (1984). The ecology of eelgrass meadows of the Atlantic coast: a community profile. U.S. Fish Wildl. Serv. Res. Rep. FWS/OBS-84/24

Thayer, G. W., Wolff, D. A., Williams, R. B. (1975). The impact of man on seagrass. Am. Scient. 63: 288-296

Twilley, R. R., Kemp, W. M., Staver, K. W., Stevenson, J. C., Boynton, W. R. (1985). Nutrient enrichment of estuarine submersed vascular plant communities. I. Algal growth and effects on production of plants and associated communities. Mar. Ecol. Prog. Ser. 23: 179-191

Manuscript first received: May 10, 1992

Revised version accepted: December 28, 1992 